\title{
Ice Stream C, Antarctica, sticky spots detected by microearthquake monitoring
}

\author{
S. Anandakrishnan and R. B. Alley \\ Department of Geosciences and Earth System Science Center, Pennsylvania State University, University Park, PA \\ 16802, U.S.A.
}

\begin{abstract}
Microearthquakes at the base of slow-moving Ice Stream C occur many times more frequently than at the base of fast-moving Ice Stream B. We suggest that the microearthquake source sites are so-called "sticky spots", defined as limited zones of stronger subglacial material interspersed within a weaker matrix. The faultplane area of the microearthquakes $\left(O\left(10^{2} \mathrm{~m}^{2}\right)\right)$ is therefore a measure of the size of the sticky spots. The spatial density of the microearthquakes $\left(O\left(10 \mathrm{~km}^{-2}\right)\right)$ is a measure of the distribution of sticky spots.

The average stress drop associated with these microearthquakes is consistent with an ice-stream bed model of weak subglacial till interspersed with stronger zones that support much or all of the basal shear stress. We infer a weak inter-sticky-spot material by the large distances $\left(O\left(10^{3} \mathrm{~m}\right)\right)$, relative to fault radius, to which the microearthquake stress change is transmitted.
\end{abstract}

\section{INTRODUGTION}

Icc Strcam C, West Antarctica, one of the Ross ice steams, has slowed to speeds of between 1 and $13 \mathrm{ma}^{-1}$ (Whillans and others, 1987) within the last two centuries (Rose, 1979; Shabtaie and Bentley, 1987; Retzlaff and Bentley, 1993). Neighboring Ice Stream B flows rapidly (400$800 \mathrm{ma}^{\mathbf{1}}$ even though it is grossly similar to Ice Stream $\mathrm{C}$ in physical dimensions, accumulation and temperature Shabtaie and others, 1987). The likcly candidates for the restraining stress are the sides and the bed of the ice stream. In this paper we concentratc on the bed.

The sources of restraining stress at the bed are some unknown combination of the rheological properties of the till and the so-called "sticky spots" at the glacial/ subglacial interface (Bindschadler and Scambos, 1991; Alley, 1993; Whillans and Van der Veen, 1993). The sticky spots are regions of the bed where shear stress is concentrated and that, in sum, balance some or all of the driving stress. The deforming till beneath Ice Stream B Blankenship and others, 1987; Engelhardt and others, 1990) permits fast flow but may provide little restraint to the driving stress of Ice Stream B (Alley and Whillans, 1991). Thus, the sticky spots may be important in basal drag.

Wc assume that conditions beneath Ice Stream C, when it flowed rapidly ( $>130$ a ago), were similar to those currently bencath fast-flowing Ice Stream B. Thus, by extension, differences between Ice Streams B and C today are analogous to differences between Ice Stream $\mathrm{C}$ today and its condition two centuries ago. Identifying the critical parameter(s) that differentiate Ice Streams B and C could aid in developing thcorics for the shut-down of Ice Stream C. One of the most striking differences between the two ice streams is the rate, distribution and size of basal microearthquake activity.

The basal events are two orders-of-magnitude more numerous, 1-2 orders-of-magnitude larger moment, and more widely spatially distributed bencath Ice Stream C as compared to Ice Stream B Anandakrishnan and Bentley, 1993). The events beneath both ice streams share the same depth-zone (the base of the ice) and the same focal mechanism (low-angle thrust faults in the direction of local driving stress), suggesting that the principal directions of stress at the bed are similar in both cases. We do not insist on this interpretation because slip on preexisting faults is not necessarily determined by the stress directions. Nonetheless, we suggest that the difference in microcarthquake rate and size is duc to a difference in material properties most notably friction) and the difference in spatial density is due to a difference in either friction or till rheology.

Alley and others (1994) proposed that an important parameter in controlling the velocity of ice streams is the state of lubrication of sticky spots. They hypothesized that basal water has been diverted away from Ice Stream C, resulting in a disruption of a Wecrman-type water film. This water film (in their hypothesis) existed when Ice Stream C flowed fast but is currently either non-existent or discontinuous. In either case, the lubrication of sticky spots is reduced and Ice Stream G shuts down.

As we now demonstratc, the till rhcology (as determined by porosity) is unlikely to have been much affected by the disruption of the water film. Thus, the sticky spots are as important to the dynamics of Ice Stream C flow as they are for Ice Stream B.

We now demonstrate that dewatering the till (changing the porosity from 40 to $30 \%$ ) by conduction 
through the till requires $O\left(10^{6}\right.$ a). The volumetric flow rate $u$ through a permeable medium is given by Darcy's law as $u=-K \mathrm{~d} H / \mathrm{d} x$, where $K$ is the hydraulic conductivity $\left(K=10^{-6} \mathrm{~ms}^{-1}\right)$ and the hydrologic potential gradient $\mathrm{d} H / \mathrm{d} x=10^{-3}$. The flow rate per unit width is $q=u \times h$, where $h$ is the thickness of the permeable till. For a $10 \mathrm{~m}$ thickness of till, $q=10^{-8} \mathrm{~m}^{2} \mathrm{~s}^{-1}$, and to move $10 \%$ of the water to the grounding line $\left(10^{5} \mathrm{~m}\right)$ would require $t=\left(10^{5} \mathrm{~m} \times 10 \mathrm{~m} \times 0.1\right) / q=10^{6} \mathrm{a}$.

If, on the other hand, channels were to form at the base of the ice stream, the till would dewater upwards and that water would be quickly removed. However, after the top few centimeters of till had dewatered, the hydraulic conductivity of that zone would decrease by many orders - to magnitude (Boulton and Hindmarsh, 1987) and slow the dewatering process for the deeper till. The cap over the till would tend to maintain the porosity of the till on timescales on the order of centuries. We argue that an unconsolidated till at the bed of Ice Stream $\mathrm{C}$ that permitted fast ice flow 130 a ago would likely still exist. Supporting these theoretical considerations is the discovery of a $20 \mathrm{~km}$ wide band of presumed dilatant till beneath Ice Stream C flanked by till of indeterminate dilatancy (Atre and Bentley, 1993j. These results arc from an analysis of the phase-reversals of reflections from the bed during an explosive-source scismic profile on Icc Stream C.

\section{ANALYSIS}

During the austral summer of 1987-88, a seismic array recorded 161 thrust-faulting events from the base of Ice Stream C (Anandakrishnan and Bentley, 1993). All the events shared the same fault-plane solution of slip at an angle of $30^{\circ}$ to the long axis of the ice stream at a dip of a few degrees. All the events were therefore subject to the same stress ficld that is duc almost exclusively to the surface and basal slopes of the ice stream.

The events were within $10 \mathrm{~m}$ of the bed of the ice strcam, and Anandakrishnan and Bentlcy (1993) argued that they are most probably either in the subglacial region or at the interface, rather than within the ice. They argued that under the low strain rates present at the basc of Ice Stream C, and the high temperature (close to or slightly below freezing), it is unlikely that ice would fracture (Hobbs, 1974). Rather, the basal shear stress is transmitted to the bed. Events on the interfacc between the ice and sediment would have moments determined by the average source parameters of the two media. We consider this situation most likely and use a moment determination that is intermediate between one calculated for ice and one calculated for the sediment.

The threshold-detection algorithm for the Icc Strcam C events was used in two modes: single-station trigger and dual-station trigger. The single-station trigger would initiate recording of all seismograms in the array when the trigger station detected an event. To discriminate against small events, we occasionally uscd dual-station triggering where two widely separated stations must both detect an cvent before recording was initiated. The singlestation-trigger events were on avcrage smaller (lower seismic moment) than the dual-station-trigger cvents, but still had excellent signal-to-noise ratios $(\mathrm{SNR}>18 \mathrm{~dB}$ ).

\subsection{Time-series analysis}

We extract from this data set a list of event-occurence times $t_{i}$, inter-event times $\tau_{i}=t_{i}-t_{i-1}$, and the associated successive-event horizontal separation $d_{i}=\mid \mathbf{r}_{i}-$ $\mathbf{r}_{i-1} \mid$ where $\mathbf{r}_{i}$ is the horizontal position of event $i$ and $|\cdot|$ denotes the magnitude of the enclosed vector. We include event $i$ if events $t_{i}$ and $t_{i-1}$ were not separated by any down-time of the recording system. This reduced the set to 53 events.

The counting statistic $n(T)$ is defined as the number of events in a time window of length $T$ (Papoulis, 1984). The probability distribution function $P(n ; T)$ is a Poisson distribution if all the events arc independent. The horizontal separation $d_{i}$ we defined for each pair of events $t_{i}, t_{i-1}$ is now used to test whether the events are described by a Poisson process at all scales. That is, we now examine whether there is some critical event separation $D$ such that the sub-set described by $d_{i} \leq D$ is not distributed as a Poisson, but events described by $d_{i}>D$ are Poisson. Certainly $D<\infty$ must exist because events at some (possibly great) distance must be independent. If $D=0$, then the microearthquake events are independent one from another at all distances. We call the distance $D$ the "radius-of-influence" (ROI) of a microearthquake.

We test whether a distribution is Poisson by a $\chi^{2}$ test and reject the hypothesis of Poisson if the goodness-of-fit parameter $q$ is small. The goodness-of-fit parameter $q=Q\left(\chi^{2} \| \nu\right)$ is the probability that the observed chisquare will exceed the value $\chi^{2}$ by chance even though the model is correct; the function $Q$ is the $\chi^{2}$ distribution function (Walpole and Myers, 1975). Because of the small sample size, we reject the Poisson hypothesis if $q$ is $O\left(10^{-10}\right)$ but accept the hypothesis for $q$ that is $O\left(10^{5}\right)$. This is not entirely arbitrary; examination of Figure 1 demonstrates that $q$ tends to fall into two regions: $q \geq 10^{3}$ and $q \ll 10^{-10}$.

The counting distribution $n(T)$ depends on the

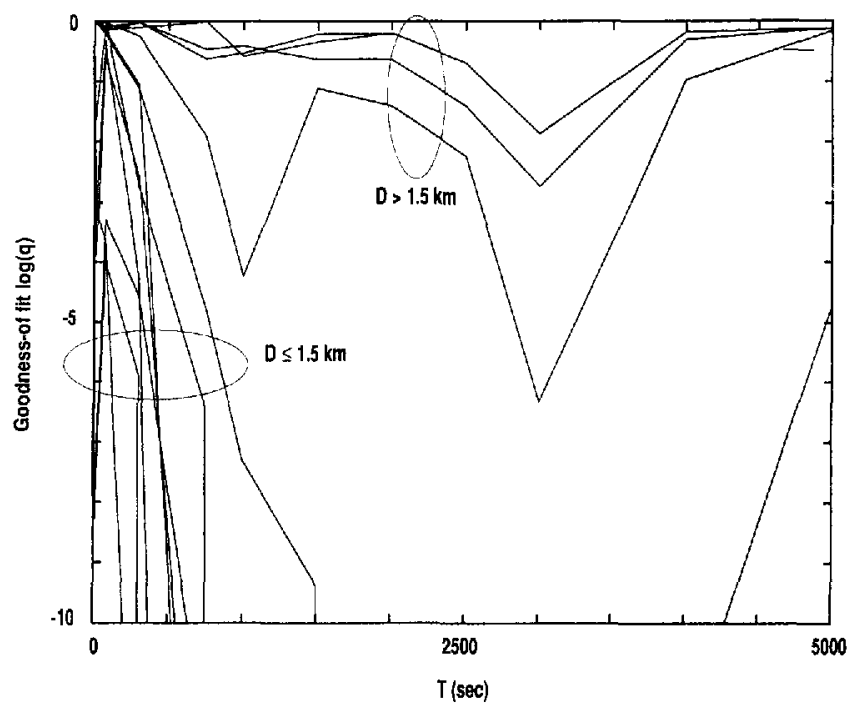

Fig. 1. Plot showing log of the $\chi^{2}$ goodness-of-fil parameter $q$ versus the counting time $T$. The different curves are for different values of $D$, the critical distance between successize events. 
counting length $T$. For $T$ short compared to mean interevent time $\tau$, any distribution will be well described by a Poisson (Papoulis, 1984). Thus, we test for Poisson distributions by varying $T$ from $T \ll \tau$ to $T \gg \bar{\tau}$. If we cannot reject the Poisson hypothesis at all $T$, then we must accept it.

Figure 1 is a plot of $q$ vs counting time $T$. The range of $T$ is from 1 s to $5000 \mathrm{~s}$ with $\bar{\tau} \approx 800 \mathrm{~s}$. The different lines are for the sub-set $d_{i}<D$, with $D$ ranging from $100 \mathrm{~m}$ to $2500 \mathrm{~m}$. For $D \leq 1500 \mathrm{~m}$, we reject the hypothesis of Poisson distribution because $q \ll 10^{-5}$ at some $T$ (generally at $T \gtrsim \bar{\tau}, q$ drops sharply from $O\left(10^{5} ;\right.$ to $O\left(10^{-20}\right.$ ) or less). Note that, in accordance with theory, $q=1$, indicating a good fit with the Poisson distribution at $T=1 \mathrm{~s}$ a time much shorter than the mean inter-event time $\bar{\tau}$ ). For $D>1500 \mathrm{~m}$, the hypothesis of Poisson distribution cannot be rejected. The threshold level of $q=10^{-5}$ is somewhat arbitrary, but it is clear that for the three curves marked $D>1500$, the hypothesis of Poisson is more plausible than for the other curves, which are marked $D \leq 1500 \mathrm{~m}$. Though the number of data points for the large-separation curves $(D>1500 \mathrm{~m})$ is small $n=15)$, the goodness-of-fit parameter $q$ is large $\left(\geq 10^{2}\right)$ at most $T$ and never drops to $10^{20}$ as do the curves marked $D \leq 1500 \mathrm{~m}$.

\subsection{Spectral characteristics}

Using the spectrum of the compressional-wave arrival, Anandakrishnan and Bentley (1993) calculated the seismic moment of the events using the methods of $\mathrm{Aki}$ and Richards (1980) and Brune (1970). The seismic moment calculation is a function of source density and shcar-wave velocity. Assuming source parameters intermediate between ice and sediment, we calculate that the seismic moments $M_{0}$ for the 161 events beneath Ice Stream C averaged $\bar{M}_{0}=10^{7} \mathrm{Nm}$.

Frequency analysis of the seismic wave forms using the method of Brunc (1970) and Madariaga (1983) can be used to calculate the source radius. In one generally used method (Aki and Richards, 1980), the spectrum of the displacement wave form is fitted to a function of the form $u_{0} /\left(1+\left(\omega_{0} / \omega\right)^{2}\right)$ where $u_{0}$ is related to the moment and is a robust measure thereof) and $\omega_{0}$ is related to the faultplane area $S$. The angular frequencies $\omega$ and $\omega_{0}$ are defined as $\omega \equiv 2 \pi / f$ and $\omega_{0} \equiv 2 \pi / f_{0}$, where $f$ and $f_{0}$ arc spectral frequencies in $\mathrm{H}_{z}$. Calculations of fault-plane area are highly model-dependent and therefore fault area $S$ is not as well constraincd as moment $M_{0}$, but is good to an order-ofmagnitude. We estimate the fault area as $S \sim 10^{2} \mathrm{~m}^{2}$.

Finally, using the moment and fault-planc arca, we calculate the stress drop associated with the events by $\Delta \sigma \approx M_{0} / a L^{3} \approx 10^{5}$ Pa where $L \sim \sqrt{S}$ is the characteristic dimension (radius or length) of the fault and $a=0.1$ is a fudge factor for fault shape and could go to 0.3 (Kostrov and Das, 1989). Again, because of the uncertainty in $L$, the stress-drop $\Delta \sigma$ is an order-ofmagnitude approximation.

Using simple Darcy's law arguments, we demonstrated that the till is likely to retain a high porosity regardless of the state of the basal water system. The results from the microearthquake time-series analysis suggest the same conclusion. The ROI for events at the bed of Ice Stream C is $1.5 \mathrm{~km}$. A qualitative interpretation of this result is that the intervening material has low strength. Work in progress is aimed at quantifying a relation between ROI and sediment rigidity.

We now estimate whether the driving stress of the ice streams is balanced cntircly by the stress drops of the microearthquakes. We assume that the bed alone supports the driving stress of the ice stream and ignore the rolc of the sides of the ice stream.

The shear stress at the base of the ice is given by $\sigma_{\mathrm{i}}=\rho g h \alpha \approx 0.01 \mathrm{MPa}$ (Paterson, 1981) where $\rho=$ $10^{3} \mathrm{~kg} \mathrm{~m}^{3}$ is the density of ice, $g=10 \mathrm{~ms}^{-2}$ is the acceleration due to gravity, $h=10^{3} \mathrm{~m}$ is the ice thickness and $\alpha=10^{-3}$ is the surface slope. The mean separation of events is approximately $400 \mathrm{~m}$. If we assume that the inter-sticky-spot material is weak, then the stress of a $(400 \mathrm{~m})^{2}$ area is concentrated on one sticky spot (on average). The force on each such sticky spot is $F=$ $(400 \mathrm{~m})^{2} \times 0.01 \mathrm{MPa}=1.6 \times 10^{9} \mathrm{~N}$. The area of each of the sticky spots is $S \sim 10^{2} \mathrm{~m}$ and thus the shcar stress on each sticky spot is $\sigma=F / S \sim 10 \mathrm{MPa}$. The seismically measured stress drop is $0.1 \mathrm{MPa}$.

Theories of partial stress drop hypothesize that an earthquake only releases a fraction of the tocal applied stress on the fault. Estimates of the fraction vary from 1 to $10 \%$ Brune, 1970). Thus, if partial stress drop is $1 \%$, then the driving force of the ice stream is entirely balanced by the sticky spots; if it is $10 \%$ then only $10 \%$ of the driving force is balanced by sticky spots.

\section{CONGLUSION}

Microearthquakes at the bed of Ice Stream C occur at discrete zones of high friction that are separated by lowstrength till. These sticky spots balance most, if not all, of the driving stress of the ice stream and are strong candidates for the mechanism for restraining ice flow. We have demonstrated that, cven though the fault radius of an individual microearthquake event is $O(10 \mathrm{~m})$, the cvents can modify the stress at locations up to $1.5 \mathrm{~km}$ away. This argues for a weak intervening material.

For sticky spots with a mean separation of $400 \mathrm{~m}$, a mean radius of $10 \mathrm{~m}$ and with a weak intervening till, the sticky spots support 10-100\% of driving stress for ice flow. Thus, we suggest a model of the base of the ice streams that consists of a weak, unconsolidated till interspersed with discrete zones of higher strength that are on the order of $10^{2} \mathrm{~m}^{2}$ in area. These zones have a spatial density. on the order of $10 \mathrm{~km}^{-2}$. The frictional character of these sticky spots is a possible candidate for the controlling parameter for ice-stream flow speed.

The suggested diversion of Ice Stream C basal water (Alley and others, 1994) and the consequent slowing of Ice Stream $\mathrm{C}$ is likely to have preserved the porosity of the till and the size and density of the sticky spots. The friction on the sticky spots is the only parameter likely to have changed. We suggest that sticky spots exist beneath Ice Stream B but only rarely do they manifest themselves seismically. The microearthquakes emanating from the base of Ice Stream C are the first direct evidence of the difference in frictional character of sticky spots between the fast and slow ice streams. 


\section{ACKNOWLEDGEMENTS}

We thank M.C. Teich and B. F. A. Saleh for helpful discussions about triggered-event statistics. One of us (S.A.) is supported by the Lucille and David Packard Fellowship Fund. We thank the National Science l'oundation Office of Polar Programs for additional support.

\section{REFERENGES}

Aki, K. and P. G. Richards. 1980. Quantitite seismology. Theor and methods. Now York, W. II. Freeman and Co.

Alley, R.B. 1993. In search of ice-stream sticky spots. 7. Gilaciol., $39133 \div, 447454$.

Allcy, R. B. and I. M. Whillans. 1991. Changes in the West Antarctic ice sheet. Science, 254 5034$), 959-963$.

Alley, R. B., S. Anandakrishnan, C. R. Bentley and N. Lord. 1994. A water-piracy hypothesis for the stagnation of Ice Stream C, Antarcticat. Ann. Glaciol., 20 (see paper in this rolume).

Anandakrishnan, S. and C.R. Bentley, 1993. Micro-earthquakes beneath Ice Streams B and C, West Antarcica: observations and implications. J. Glaciol, 39 133), 455-462.

Atre, S. R. and C., R. Bentley. 1993. Iaterally varying basal conditions under Icc Streams B and C. West Antartica. F. Glaciol, 39(133), $507-514$.

Bindschadler, R.A. and 1.A. Scambos. 1991. Satellite-image-derived velocity field of an Antarcic ice strcam. Setence, 252(5003), 242-246.

Blankenship, D. D., C. R. Bentley, S. T. Rooney and R. B. Alley 1987. Till beneath Ice Stream B. I. Properties derived from seismic travel lintes. 7. Geoplys. Res., 92(B9), 8903-89]1.

Boulton, G.S. and R. C.A. Hindmarsh. 1987. Sedinent delormation beneath glaciers: rheology and geological consequences. If. Geophys. Re.. 92 B Bi, 9059-9082.

Brunc, J. N. 1970. Tectonic stress and the spectra of seismic shcar waves from earthqualies. J. Geoplys. Res., 75(26), 4997-5009.
Engelhardı, H., N. Humphres, B. Kamb and N. Fahnestock. 1990. Physical conditions at the base of a fast moving Antarcic ice stream. Srience, $248(4951), 5759$.

Hobbs, P. V. 1974. Ice phisir. Oxford, Clarendon Press.

Kostrov, B. V. and S. Das. 1989. Princifles of earthueste some mechanis. Cambridge, Cambridge University Press.

Madariaga, R. 1983. Farthquake source theory: a review: In Kanamori. H., ed. Earthquaks: obsertation, theory and interpretation. New York. International School of Physics "Finrico Fermi", North-Holland Publishing, $1-41$.

Papoulis, A. 1984. Probability, random iarables and stochatic processes. Secund edition. New York, McGraw-Hill

Paterson, W.S.B. 1981. The fressics of glaciers, Second edition. Oxford. Pergamon Press.

Retzlaff, R. and C. R. Bentley. 1993. Timing of stagnation of Icr Stream C, West Antarctica, from short-pulse radar studies of buried surface crevasses. 7. Glaciol., 39(133), 553-561.

Rose, K. 1979. Characteristics of ice flow in Maric Byrd Land. Antarctica. 7. Glaciol, 24,90), 63-75.

Shabtaic, S. and C.R. Bentlcy. 1987. Mest Antarctic ice strcams draining into the Ross Ice Shelf: configuration and mass balance. $\not$. Geophys. Res, $92(\mathrm{~B} 2), 1311-1336$.

Shabtaie, S., I. M. Whillans and C. R. Bentley. 1987. The morphologry of Ice Streams A, B, and C. West Antarctica, and their enrirons. $\dot{f}$. Geophys. Res., 92 B9), 8865-888.3.

Walpole, R. E. and R. H. Myers. 1975. Probabitity and statistics for engineers and scientists. Second edition. New York, Macmillan.

Whillans, I. M. and C.J. ran der Veen. 1993. New and improved delerminations of velocity of Ire Streams B and $C$, IVest Antarcica. 7. Glaciol., 39 133$)$, 483-190.

Whillans, I. M., J. Bolzan and S. Shabtaie. 1987. Velocity of Ice Streams B and C, Antarctica. J. Gephrs. Res., 92(B9), 8895-8902.

The accuracy of references in the text and in this list is the responsibility of the authors, to whom queries should be addressed. 